\title{
As antinomias na formaç̃a das rotinas alimentares contemporâneas: uma análise a partir das práticas sociais
}

\author{
Maycon Noremberg Schubert ${ }^{*}$ (1) \\ Sergio Schneider ${ }^{*}$ \\ Cecilia Díaz Méndez**
}

\section{Resumo}

O presente artigo analisa a formação das rotinas alimentares com foco nas práticas sociais a partir das antinomias entre o dentro/fora, prazer/obrigação e as constâncias/ mudanças, comparando dados de três países, Brasil, Reino Unido e Espanha. Os dados provêm de três projetos de investigação, conduzidos em cada um dos países, entre os períodos de 2014, 2015 e 2016, gerando informações a partir de 183 entrevistas, tratadas e codificadas. As rotinas alimentares aqui compreendidas envolvem regularidade, sequência e uso recursivo do tempo. As antinomias quanto ao comer dentro/fora e ao prazer/obrigação demostram aspectos relativos à fuga da rotina, à divisão social do trabalho e às influências que os menus de fora, ou mesmo de dentro de casa, exercem sobre a dieta alimentar, diferenciando-se, em alguns aspectos, entre os três países. É possível verificar que os condicionantes das mudanças/constâncias em torno das rotinas alimentares convergem parcialmente entre os países analisados, com mudanças mais "bruscas" na presença de filhos, nos aspectos quanto à saúde e na fase de independência dos filhos. Porém, mudanças mais "graduais" foram percebidas quanto ao paladar, à oferta de alimentos, à renda e às dinâmicas laborais. Destaca-se o cosmopolitismo britânico, o tradicionalismo espanhol, e uma "mescla" entre o cosmopolitismo e tradicionalismo no Brasil.

Palavras-chave: rotinas alimentares, sociologia do comer, Teoria das Práticas Sociais, sociologia da alimentação.

* Universidade Federal do Rio Grande do Sul, Porto Alegre, RS, Brasil.

** Universidad de Oviedo, Astúrias, Espanha. 


\section{Antinomies in the formation of contemporary food routines: an analysis grounded on social practices}

\section{Abstract}

The present article analyses the formation of food routines with a focus on social practices. The analysis is based on the antinomies between inside/outside, pleasure/ obligation and constancy/changes, and compares empirical results obtained from three countries: Brazil, the United Kingdom and Spain. The data come from three research projects, conducted in each country, from 2014 to 2016, which generated information from 183 interviews that was treated and coded. The considered food routines include regularity, sequence and recursive use of time. The antinomies regarding eating home/out-of-home and pleasure/obligation showed aspects related to escape from routine; social division of labour and influences that either out-ofhome or home menus have on the diet; such aspects showed differences in some respects among these three countries. It was observed that the determinants of changes/constancy in eating routines somewhat converge among the three countries, with more "abrupt" changes in the presence of children, in terms of health and in the stage of children's independence. On the other hand, more "gradual" changes were noted in connection with taste, food supply, income and work dynamics. Empirical findings point to a British cosmopolitanism, Spanish traditionalism, and a "mix" of cosmopolitanism and traditionalism in Brazil.

Keywords: food routines, sociology of eating, Social Practice Theory, sociology of food.

\section{Introdução}

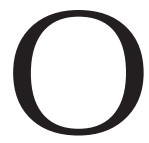

presente artigo aborda o tema do comer a partir de uma visão pragmática das práticas sociais, tendo em vista que as teorias em torno do conceito de ação, mais tradicionais no âmbito das Ciências Sociais, têm sido insuficientes. Por um lado, essas tendem a uma abordagem culturalista, com excessivo foco nos símbolos e na identidade, esquecendo que a maior parte do consumo de alimentos é ordinário e inconspícuo, além de prestar pouca - ou quase nenhuma - atenção aos objetos e às tecnologias como forças materiais que influenciam as práticas sociais (Neuman, 2019). Por outro lado, as abordagens individualistas, 
racionalistas e instrumentais, advindas principalmente do campo da economia neoclássica, isolam as decisões individuais dos contextos sociais, além de torná-las a-históricas, dispersas e finalísticas, exagerando, assim, a deliberação e tomada de decisão dos indivíduos (Warde, 2017). Desse modo, uma análise em nível mesoanalítico, sem optar pelo individualismo metodológico ou holismo culturalista, parece uma abordagem teóricometodológica interessante para os estudos sobre alimentação, especialmente sobre o comer. A Teoria das Práticas Sociais surge como uma opção de extrema relevância para essa tarefa, a partir de uma corrente de pensamento pós-positivista, assentada na perspectiva pragmática de interpretação da realidade social (Schatzki, 1996; Shove et al., 2012; Warde, 2016).

A escolha de trabalhar com o conceito de antinomias decorre do fato de que o ato de comer é essencialmente constituído por contradições aparentes, que variam em termos normativos e contextuais, sendo esse um conceito operacional já utilizado por Warde (1997) e Barbosa (2007). ${ }^{1}$

Analisar as práticas do comer em três países, em diferentes situações e momentos do cotidiano, demanda uma análise relacional e ampla, sem focar, necessariamente, em somente uma perspectiva, como ocorre, por exemplo, nas abordagens culturalistas, que priorizam essencialmente as questões simbólicas. Como forma de demonstrar essas inter-relações complexas, a partir das constatações mais destacadas que surgem da realidade empírica, serão analisadas no presente artigo as antinomias que se estabelecem entre o dentro/fora, prazer/obrigação e constâncias/ mudanças, quanto às práticas do comer.

\footnotetext{
1 "[...] antinomies of taste provide a systematic basis for these contradictory messages. These oppositions - novelty and tradition, health and indulgence, economy and extravagance, care and convenience - are values which can legitimize choice between foodstuffs" (Warde, 1997, p. 55).

“Da mesma forma, como no estudo de Warde (1997), essas antinomias não se aplicam apenas à escolha de cardápios, mas estão presentes em várias dimensões da vida cotidiana, embora adquiram especificidades quando aplicadas à alimentação. São elas: praticidade/ improvisação versus planejamento/preferências individuais; restrição e liberdade (que se subdivide em saudabilidade/beleza versus prazer/sabor e economia versus extravagância); e, por fim, temos rotina/tradição versus variedade/novidade" (Barbosa, 2007, p. 97).
} 
$\mathrm{O}$ ato de comer, em meio a esses processos mais amplos e movimentos socio-históricos, parece algo naturalizado em nosso cotidiano, pois presume envolver uma simples decisão, uma escolha, ou mesmo uma prática corriqueira, habitual, para alguns indivíduos. No entanto, ao olhar de forma mais detalhada, relacionando esse ato a diversas outras questões da vida social - como trabalho, família, lazer, corpo, renda, gosto, entre outros fatores -, percebe-se o quão complexa se torna essa escolha, e suas diversas implicações. Assim, os significados e as motivações em torno do ato de comer variam de acordo com o perfil socioeconômico, o ambiente institucional, os estilos de vida que os indivíduos almejam, a sociabilidade engendrada, o uso de tempo, os espaços em que se come, o menu que se escolhe ou, ainda, os processos de incorporação envolvidos. Por certo, o comer é um fato social de grande importância, demandando um "olhar" ainda mais aplicado das Ciências Sociais (Warde, 2016; Southerton, 2012; Warde; Martens, 2003).

Destaca-se, ainda, que o fenômeno social da alimentação tem ganhado proeminência nas agendas de pesquisa, nos mercados de consumo e no dia a dia da população, especialmente nas últimas três décadas (Kraig; Sen, 2013). Temas como saúde, fome, luta e resistência social, hedonismo, reconhecimento, alienação, mercados e poder, dentre outros, têm dado os contornos das práticas sociais que permeiam cada "garfada" do que vem a ser considerado "comida" na sociedade contemporânea, revelando traços da realidade social tangíveis ao modo de reprodução social, cultural e econômica dos indivíduos e seus coletivos (Simmel, 2004 [1910]).

Nesse sentido, o objetivo deste artigo é discutir a formação das rotinas alimentares com base nas práticas sociais, cotejando Brasil, Reino Unido e Espanha, com foco nas mudanças e nas dissoluções de determinadas "configurações sociais", sedimentadas - tanto no imaginário coletivo quanto nas interdições do cotidiano - pelas práticas sociais.

Resumidamente, o artigo está organizado em quatro seções, além dessa breve introdução. A primeira seção trata das abordagens teóricas utilizadas para interpretar os dados empíricos; a segunda trata da metodologia, em 
que é discutida a forma de obtenção e análise dos dados. Segue-se uma longa seção que apresenta as análises dos dados empíricos, subdivida em três subseções que tratam das antinomias, dentro/fora, prazer/obrigação e mudanças/constâncias. Por fim, apresentam-se as conclusões sobre as reflexões traçadas ao longo do artigo, tanto empíricas quanto teóricas.

\section{A teoria das Práticas Sociais e suas aplicações no campo dos estudos alimentares}

As origens filosóficas da Teoria das Práticas Sociais (TPS) advêm das incursões teóricas de Wittgenstein, com sua gramática pragmática, e Heidegger, com sua analítica existencial. Tais autores causaram, e ainda causam, profundas influências no campo da fenomenologia e da praxiologia (Peters, 2020). Sob essa vertente filosófica, a Teoria das Práticas se apresenta com uma alternativa entre as abordagens individualistas e holistas. Em relação às abordagens individualistas, rejeita o utilitarismo centrado na racionalidade, nas estratégias e no estado mental dos indivíduos. Já das abordagens holistas, rejeita a visão funcionalista e evolucionária, centrada em estruturas abrangentes e totalizantes (Warde, 2013; Shove et al., 2012; Nicoliny, 2012; Schatzki, 1996; Reckwitz, 2002b).

Há, pelo menos, quatro abordagens mais proeminentes, no momento, sobre a Teoria das Práticas. Com relação às suas bases ontológicas, não há discordâncias, sendo a unidade de análise as próprias práticas sociais. Todavia, há diferenças significativas entre algumas abordagens que recaem, principalmente, sobre as regularidades, as regras e a dimensão teleológica das práticas sociais ${ }^{2}$. Outro elemento importante é que as práticas sociais se constituem a partir dos dizeres e fazeres como estruturas essenciais da "performatividade" das ações sociais, conectados aos arranjos materiais (os outros entes que não os humanos). ${ }^{3}$

Para este artigo, será aplicada a abordagem de Schatzki (1996, 2001, 2002, 2013, 2019), que define as estruturas elementares - ontológicas - do

${ }^{2}$ Ver Schatzki (2017).

${ }^{3}$ Ver Shove et al. (2012), Reckwitz (2002b) e Nicoline (2012). 
quem vem a ser uma prática social, a partir de três mecanismos que conectam os dizeres e fazeres: entendimento prático, regras e estrutura teleoafetiva. ${ }^{4}$

Por "entendimento prático", refiro-me a saber que ações corporais realizar (em determinadas circunstâncias) para cumprir ações específicas. "Regras" são diretrizes, avisos e ordens formuladas. Uma "estrutura teleológica", entretanto, é uma série de finalidades estabelecidas ou aceitáveis, coordenadas por meio de uma série de projetos estabelecidos ou aceitáveis juntamente com ações a serem realizadas para que tais fins sejam alcançados. E "entendimentos gerais" são entendimentos ou percepções de questões gerais relativas ao desenrolar da prática (Schatzki, 2013, p. 34). ${ }^{\mathbf{5}}$

Schatzki (2001) argumenta, ainda, que a vida social transpira o que ele caracteriza como sendo um "conjunto arranjado de práticas"6 que, por sua vez, irá formar um "complex practice plenum" (Schatzki, 2019, p. 27). Desse modo, os significados/identidades não são produtos das diferenças, esquemas abstratos, ou alguma relatividade atribuída, mas repousam sobre regimes de atividades e inteligibilidade chamados de práticas (Schatzki, 2002).

De forma aplicada à Teoria das Práticas, Warde (2016) argumenta sobre a necessidade de se pensar o comer não somente como um tema, como tem sido tratado por Sahlins, Bourdieu, Ilmonen, ou Douglas, mas como objeto de uma teoria científica capaz de explicar a realidade social a partir das práticas alimentares. Para o autor (2016, p. 58), “Qualquer teoria geral sobre o comer precisa explicar a relação entre o consumo alimentar, processos corporais e arranjos sociais. Estes são os elementos básicos que

${ }^{4} \mathrm{O}$ termo "teleoaffective" vem da união do conceito "teleológico" de Aristóteles, orientado aos "fins", e de "afetividade" em Heidegger, orientado pelas "motivações", ambos determinados pela inteligibilidade prática (Schatzki, 2001, p. 60).

${ }^{5}$ No original: "By 'practical understanding, 'I mean knowing which bodily actions to perform (in particular circumstances) in order to accomplish specific actions. 'Rules' are formulated directives, admonishments, and edicts. A 'teleological structure,' meanwhile, is a range of prescribed or acceptable ends, coordinated with a range of prescribed or acceptable projects, together with actions to be carried out in order for those ends to be achieved. And 'general understandings' are understandings or senses of general matters pertinent to goingson in the practice." (Schatzki, 2013, p. 34).

${ }^{6}$ No original: practice-arrangement bundles. 
uma explicação sociológica sobre as performances do comer deve abordar" ${ }^{7}$ Warde organiza sua argumentação em torno de três categorias analíticas, a partir das quais apresenta uma explicação geral sobre a teoria do comer, buscando desvelar os elementos básicos das performances que compõem as práticas sociais envolvidas:

a. os eventos e as ocasiões se constituem a partir de três dimensões - o tempo, a localização e a companhia - as quais, por sua vez, geram significados culturais e sociais em relação às performances do comer, a partir das suas justaposições e permutações;

b. a comida, os menus e os pratos, juntos, definem o que é elegível comer; ou seja, para além de uma escolha individual, esses elementos conformam um padrão social e cultural detectável nas performances relativas ao comer; e

c. os processos de incorporação envolvem questões como desordens alimentares, disjunções entre hábitos pessoais enraizados com padrões sociais distintos, dietas (autodisciplina e autocontrole do corpo) e modos à mesa.

Em síntese, tais conceitos se apresentam sob uma perspectiva pragmática pós-positivista, cuja ênfase recai na relação dos indivíduos e seus coletivos com o mundo material e em como, a partir daí, constituem determinados conjuntos arranjados de práticas, que perduram no tempo. Conjuntos que, nas abordagens mais tradicionais das Ciências Sociais, seriam classificados como estruturas sociais.

\section{Metodologia de pesquisa}

O presente artigo se assenta na necessidade de avançar em estudos comparados que permitam demonstrar em que medida determinados

${ }^{7}$ No original: "Any general sociological theory of eating needs to explain the relationship between foods consumed, bodily processes and social arrangements. These are the basic elements which a sociological explanation of performances of eating must address" (Warde, 2016, p. 58). 
fenômenos sociais - neste caso, o comer - se manifestam em determinados contextos sociais cujas características culturais se apresentam de maneira bastante específica em um dado território ou situação, ou ainda, apresentam tendências de mudanças sociais mais amplas, que podem ser compreendidas e analisadas como tendências próprias da modernidade e integradas a teorias sociológicas mais extensas, que expliquem mudanças sociais em curso (Díaz-Méndez; Espejo, 2014).

Os dados analisados neste artigo advêm de projetos de pesquisas desenvolvidos por grupos de pesquisa em cada país aqui analisado. A escolha dos países resultou da oportunidade de compartilhar dados empíricos, em razão das redes sociais estabelecidas entre pesquisadores. Essas redes se consolidaram por meio de missões de trabalho, doutoramento sanduíche, além de eventos nacionais e internacionais.

Do Brasil, foi cedida parte dos dados de três edições das pesquisas sobre Hábitos alimentares dos brasileiros (2005, 2011 e 2015). Esses projetos foram conduzidos pela empresa Toledo e Associados. Ao todo, os dados analisados contaram com 101 entrevistas de grupos focais, nos quais os interlocutores variavam entre classes sociais, idade e sexo. Com respeito às fontes de dados primários do Reino Unido, obteve-se acesso aos dados de pesquisa do projeto Re-visiting "eating out" in London, Preston and Bristol (UK) 1995-2015, dentro do qual se realizaram 31 entrevistas semiestruturadas, em três cidades do Reino Unido - Bristol, Preston e Londres. Por fim, os dados primários da Espanha foram cedidos pelo projeto La alimentación fuera del hogar en Europa: un análisis comparado de los modelos alimentarios extradomésticos en España y Reino Unido, no qual foram realizadas 51 entrevistas semiestruturadas.

As amostras de cada um dos projetos de pesquisa foram obtidas de forma distinta. No Brasil, a amostra cobriu sete capitais (São Paulo, Brasília, Rio de Janeiro, Recife, Curitiba, Belo Horizonte e Belém). A primeira edição incluiu 45 grupos focais, com uma média de oito a dez participantes por grupo, com idades variando de 17 a 64 anos, sendo cinco grupos focais por capital. A segunda e a terceira edições incluíram 28 grupos focais, sendo 
quatro por capital e compostos por indivíduos também com idades entre 17 e 64 anos, e composição média de oito a dez indivíduos por grupo. No Reino Unido foram realizadas 11 entrevistas em Bristol, dez em Preston e dez em Londres, sendo importante notar que essa pesquisa foi uma reedição, atualizada, da pesquisa realizada em 1995 pelo mesmo grupo de pesquisa alocado no Sustainable Institute Consumption. ${ }^{8}$ Já os dados da Espanha se dividiram em entrevistas realizadas na cidade de Valência (nove), na cidade de Lugones (cinco), na cidade de Madri (13), na cidade de Nava (seis), e na cidade de Valladolid (18), tendo sido coordenado pelo grupo de pesquisa em Sociologia de la Alimentación. ${ }^{9}$ Algumas entrevistas na Espanha foram realizadas com mais de um participante, muitas vezes o casal, o que gerou uma participação total de 85 indivíduos em 51 entrevistas. Importa frisar que os dados brutos desses projetos de pesquisa foram obtidos pelos autores do artigo, alguns participando diretamente na coleta e sistematização, como o caso da Espanha, outros, indiretamente, acompanhando a pesquisa por meio de missões acadêmicas, como nos casos do Reino Unido e do Brasil.

Como é possível notar, há diferenças metodológicas na obtenção dos dados entre os três projetos de pesquisa, pois são projetos distintos. Não são amostras representativas de toda a população de cada um dos países, porém, possuem um grau de confiabilidade alto, pois foram projetos aprovados e financiados por órgãos de pesquisa oficiais e geraram dados analisados por grupos de pesquisas respeitáveis e reconhecidos no mundo todo, dentro do campo da Sociologia da Alimentação. Apesar das diferenças, o banco de dados é relativamente grande, e permite, mesmo com seus limites de representação, estabelecer análises comparadas que podem servir de base para estudos futuros mais aprofundados e com metodologias mais específicas, direcionadas a um tema e/ou a um dos países aqui analisados.

Em síntese, no conjunto das informações disponibilizadas pelos projetos de pesquisa de cada país formou-se um banco de dados com 183 entrevistas,

${ }^{8}$ https://www.sci.manchester.ac.uk/research/projects/eating-out/

9 http://www.unioviedo.es/socialimen/ 
sendo 31 do Reino Unido (entrevistas individuais), 101 do Brasil (entrevistas grupais) e 51 da Espanha (entrevistas com casais e individuais). Esses dados foram codificados e analisados a partir do programa chamado Maxqda, na sua versão Plus 12. Ao todo, foram codificados 11.889 segmentos, o que resultou em mais de 4.500 páginas de dados qualitativos. Por meio da codificação, buscou-se construir "padrões significativos dos fatos", comparando diferentes partes dos dados, a fim de encontrar atributos comuns, diferenças ou mesmo relações entre eles (Kelle, 2002).

As categorias empíricas foram elaboradas de maneira não apriorística, ou seja, foram criadas a partir das codificações e das análises em torno das entrevistas, seguindo as recomendações de análise de conteúdo de Bardin (2011). Contudo, as referências correspondentes às abordagens teóricas foram fundamentais para a formulação dessas categorias analíticas e das instâncias empíricas. A escolha pelo método comparativo tornou-se uma opção "chave" para as reflexões que se seguem neste artigo. O método permitiu avançar nas explicações teóricas e empíricas, destacando semelhanças, singularidades, descontinuidades, regularidades e diferenças sob as quais se apresentam, em cada um dos países, as práticas em torno do comer. Mesmo que as conclusões não possam ser generalizáveis para o conjunto dos países, o exercício exploratório de análise dos dados possibilita apontar elementos que podem ser explorados em futuras agendas de pesquisa.

\section{As antinomias das práticas do comer: condicionamentos e alternâncias}

As ações em torno do comer não resultam - na maior parte do tempo -, de um desempenho consciente em torno de regras previamente prescritas, mas, em grande medida, estão alinhadas em torno de um padrão que tende a se repetir ao longo dos dias, ou mesmo dos anos, ou ainda ao longo de toda uma vida. As escolhas e o controle que os indivíduos exercem são afetados pela companhia, pelos artefatos e pelas mensagens que os cercam. As disposições para agir de uma determinada forma passam, 
necessariamente, por um processo de socialização prévia, que se manifesta em determinados ambientes sociais, os quais funcionam como gatilhos, ${ }^{10} \mathrm{a}$ partir de um conjunto de sinais dispersos pelas práticas sociais (Warde, 2016).

Nesse sentido é que as práticas sociais, em especial aquelas em torno do comer, são rotinizadas por meio de atos corporais e de discursos, da interação com os objetos e com outros indivíduos e da descrição do mundo material envolvente. Tais dinâmicas abarcam um conjunto hierarquicamente organizado de tarefas e projetos que são levados adiante pelos indivíduos e seus coletivos, especialmente no que corresponde à estrutura teleoafetiva das práticas sociais, ou seja, os fins e as motivações das práticas (Schatzki, 2002; Reckwitz, 2002a).

Porém, o comer não é uma tarefa fácil de ser realizada, como aparentemente parece ser, mesmo quando se vive em uma sociedade de abundância. Vale ressaltar que as práticas em torno do comer não se estabelecem em um vácuo social, mas estão conectadas a outras práticas sociais correlacionadas, como trabalhar, correr, estudar, socializar, namorar, dentre tantas outras. Nota-se que as práticas competem entre si pelo uso do tempo, tal como delimitam o próprio tempo enquanto um ativo a ser utilizado por elas, de forma recursiva, com influência direta sobre as rotinas alimentares (Southerton, 2012). Assim, é possível assumir que existem diferentes comportamentos relacionados a uma mesma prática em torno do comer, a partir das antinomias aqui propostas.

\section{Dentro/Fora}

Apesar de as fronteiras conceituais que separam o comer em casa do comer fora de casa serem imprecisas, como salienta Julier (2013), é fundamental compreender que tanto um como outro são interdependentes (Warde; Martens, 2003) e se constituem de forma relacional (HerreraRacionero; Lizcano, 2018).

10 Warde (2016) utiliza o termo gatilhos para explicitar que em determinadas situações, dadas as condições precisas, alguns tipos específicos de comportamento podem surgir. 
As práticas do comer em casa (dentro) e/ou fora de casa são, ao mesmo tempo, constituídas pelas rotinas alimentares e constitutivas dessas rotinas. As análises apontam diferenças e semelhanças no que diz respeito às influências do fora sobre o dentro, principalmente através do aprendizado obtido pelos indivíduos ao experimentarem algo que lhes chama a atenção - alguma novidade, algo saboroso, algo saudável etc. Mas também no sentido inverso, ou seja, do dentro para o fora, a partir do que é elaborado em casa e consumido fora - como o uso de "marmitas". Por esse fato, como salienta Warde (2016), essa análise perpassa, substancialmente, a dimensão dos eventos, especialmente quanto aos espaços.

No que corresponde às influências dos menus usufruídos fora do ambiente doméstico, a maioria dos britânicos entrevistados (3/4 dos participantes) tendem a copiar receitas dos lugares em que costumam comer fora de casa. Porém, uma parcela considerável não demonstra o mesmo interesse em copiar tais receitas (1/4). No caso dos entrevistados espanhóis, os dados revelaram haver pouco interesse em copiar receitas experimentadas fora do ambiente doméstico, sendo que apenas dois se manifestaram nesse sentido. O maior interesse dos espanhóis parece ser em experimentar algo diferente, uma comida exótica que não preparariam em casa, ou algum prato muito "rebuscado" em termos de preparo, mas que, ao mesmo tempo, é uma comida tradicionalmente apreciada. Para os entrevistados brasileiros, praticamente todos os grupos focais demostraram interesse em reproduzir em casa algo que haviam experimentado fora. Nesse caso, as opções variavam desde testar novos temperos e/ou técnicas de cozinhas, ou mesmo algum produto específico de alguma marca específica.

Interviewer: Do you ever cook something at home that you've eaten out? Do you ever take any inspiration from-? Respondent: Well, I do. I - haven't - actually I've taken a photo of the food we've eaten yesterday and I really want to do the falafels. (Mulher, 31 anos, renda $£ 10.000,00$ a 19.999,00/ ano, Bristol/Reino Unido, 2016). 
Respondedor: [...] y lo que solemos pedir, hombre, a lo mejor, suelen ser cosas que no comemos, que la elaboración digamos no lo hacemos nosotros habitualmente, por ejemplo, un rabo de toro rebozado de caramelizado. (Casal, idades entre 30 e 44 anos, € 2.500,00 a 2.999,00/mês, Valladolid/ Espanha, 2014, grifos nossos).

Entrevistador: E vocês já trouxeram alguma coisa para dentro de casa, que vocês comeram lá e quiseram implantar o prato dentro de casa ou ingredientes que vocês comeram? Entrevistados: Sashimi; Frango Frito na gordura hidrogenada; Temperos do Subway; Ervas eu comprei; aqueles hambúrgueres gourmet.; Maionese Heinz; Sal rosa, sal marinho; Geleia de pimenta eu fiz em casa; Molho do Big tast. (Entrevista com dez homens, idades entre 25 e 40 anos, renda classe A/B, Brasília/Brasil, 2015).

A estrutura teleoafetiva dessa prática é semelhante nos três países, ou seja, buscam "variar" o menu ao realizar a prática do comer fora de casa, sendo que para os entrevistados britânicos e brasileiros esse é um momento de aprendizado que influencia na confecção e composição dos menus domésticos, em uma busca por "inovação" e "adaptação". Nesse caso, a dimensão dos menus apresenta uma influência direta na escolha dos espaços em que se come.

Há ainda as interferências que ocorrem de dentro para fora de casa, com é o caso do uso da marmita, que atualmente vem ganhando importância em termos de economia de tempo e dinheiro, mas também de dietas mais individualizadas (Garcia; Gomes 2016). Entre os entrevistados brasileiros e espanhóis essa é uma prática muito comum. Já entre os entrevistados britânicos praticamente não se notou esse fenômeno.

Uma característica importante dessa prática social é a estrutura teleoafetiva que a coordena. Nos casos espanhol e brasileiro, observou-se que a principal orientação segue sendo a de economia, ou seja, "poupar" dinheiro para atender a outras prioridades individuais ou da família. Todavia, principalmente no caso brasileiro, evidencia-se que essa tendência vem, ao longo dos anos, dividindo espaço com outros objetivos, como a preocupação com a saúde, seja na melhoria da qualidade da comida, ou em razão de 
alguma dieta especial que se está seguindo, evocando determinados valores como o cuidar. Ainda no caso brasileiro, a dimensão da incorporação influencia de forma mais significativa a composição dos menus e os espaços em que se come.

Outra característica que merece destaque, por ter sido referida entre os entrevistados, é a diferença de arranjos materiais disponibilizados. Tanto no caso brasileiro quanto no espanhol, há muitos equipamentos nos locais de trabalho que facilitam, ou mesmo estimulam essa prática, como a disponibilização de espaços adequados, micro-ondas, geladeiras e cozinhas equipadas.

Entrevistador: Vocês acham que está crescendo esse fenômeno de marmita no Brasil? Entrevistado: Sim. Entrevistado: Lá no meu trabalho todo setor tem micro-ondas. Entrevistado: Hoje em dia toda empresa já tem seu refeitório pros seus funcionários. (Entrevista com dez mulheres, idades entre 24 e 40 anos, renda não informada, Belém/Brasil, 2015, grifos nossos).

Entrevistador: ¿Sueles traer comida fría? ¿Tenéis espacio para calentar y comer...? Respondedor: Sí, yo trabajo aquí en la biblioteca. Y en la biblioteca tenemos, una nevera, tenemos un microondas que nos hemos comprado nosotros. (Casal, idades entre 45 e 64 anos, renda $€ 2.500,00$ a 2.999,00, Valência/ Espanha, 2014, grifos nossos).

Essas conexões entre as práticas e os arranjos materiais são de fundamental importância para a Teoria das Práticas Sociais, pois formam a unidade que Schatzki (2013) classifica como um conjunto arranjado de práticas, sendo essa a unidade essencial, segundo o autor, em que as mudanças sociais ocorrem. Porém, essas conexões surgem em diferentes contextos sociais e são influenciadas por diferentes dimensões (menus, eventos e processos de incorporação), como observado nos dados empíricos analisados ao longo desta subseção e seguindo a abordagem de Warde (2016). 


\section{Prazer/Obrigação}

Quanto à dimensão espacial dos eventos (dentro ou fora de casa), verificou-se que o comer surge tanto como uma prática que denota obrigação - para os indivíduos que comem fora todos os dias em razão de fatores como trabalho e escola -, quanto como uma prática que denota prazer - quando realizada na casa de amigos, familiares e restaurantes. Quanto mais eventual, mais "especial" se torna determinada situação em que se realiza a prática do comer, e mais prazeroso se torna o momento, demonstrando relação com outra dimensão do comer, apontada por Warde (2016), os menus.

Em outras palavras, as rotinas alimentares parecem "cansar" ou, pelo menos, retirar prazer dos indivíduos, sendo que para que perdurem e até se reforcem, importa que sejam "quebradas" em determinados momentos. Esse fenômeno pode ser verificado nas entrevistas dos três países.

Entrevistador: ¿Os gusta comer fuera? Respondedor: Sí. Pero nos gusta comer fuera porque tampoco abusamos de ello. Yo creo que, si nos tocara comer más fuera, no... nos gustaría tanto. (Casal, idades entre 30 e 44 anos, renda $€$ 2.000,00 a 2.499,00/mês, Valladolid/Espanha, 2014, grifos nossos).

Interviewer: Do you like eating out and would you like to do it more often? Respondent: No. It's very expensive honestly and I find it too tiring unless it's a nice restaurant, but it's not something I would want to do every day. (Mulher, idade 35 anos, renda $£$ 50.000,00 - 64.999,00, Londres/Reino Unido, 2016, grifos nossos).

Entrevistador: Quais os principais motivos de se comer fora de casa? Entrevistado: Trabalho. Entrevistado: Trabalho e estudo o dia inteiro. Entrevistado: Eu tenho a possibilidade de comer em casa porque eu trabalho perto de casa, então para mim é lazer, a gente sai para jantar fora. (Entrevista com quatro homens e cinco mulheres, idades entre 17 e 24 anos, renda classe A/B, Curitiba/Brasil, 2015, grifos nossos).

Quanto à prática do cozinhar, as entrevistas do Reino Unido apresentaram uma predominância de indivíduos que não gostam de realizar 
tal prática, e a interpretam como uma obrigação, principalmente entre as mulheres. Já na Espanha, o cozinhar é majoritariamente encarado como um prazer, porém com a condição de que não seja repetitivo e que essa prática possa ser realizada com tempo. Nas entrevistas do Brasil, visualiza-se que a prática do cozinhar varia substancialmente, configurando, para uns, um prazer e, para outros, uma obrigação. Nesse último caso, especialmente para as mulheres, o comer fora se apresenta como um alívio para a rotina de tarefas domésticas.

Interviewer: So how much, you mentioned you're a bit of a foodie, so how much would you say you enjoy food and cooking and things? Respondent: I don't really enjoy it, he enjoys cooking more, I see it more as a chore. (Mulher, idade 31 anos, renda $£$ 65.000,00 - 77.999,00/ano, Bristol/Reino Unido, 2016, grifos nossos).

Entrevistador: ¿Te gusta cocinar? Respondedor: Sí. Me gusta cocinar sin... sin tener el compromiso de hacerlo. Entrevistador: Sin obligación. Respondedor: Eso, sin la obligación. Pero sí, me gusta, me gusta. (Mulher, idade entre 45 e 64 anos, renda $€ 1.000,00$ a 1.499,00, Nava/Espanha, 2014 grifos nossos).

Entrevistador: O que é cozinhar pra vocês? Que sensação dá? Entrevistado: Prazer. Entrevistado: Obrigação. Entrevistado: Necessidade. Entrevistado: Não ter que lavar nenhum prato (Entrevista com cinco homens e cinco mulheres, idades entre 17 e 24 anos, renda não informada, Belém/Brasil, 2015).

As diferenças de sentimentos de prazer ou de obrigação com respeito à prática de comer dentro ou fora de casa é visível quando é realizada nos dias de semana ou nos finais de semana. Nos dias de semana, a prática do comer fora ou em casa geralmente é percebida como uma obrigação, devido à limitação de tempo que se tem para realizá-la, a qualidade dos alimentos nem sempre é tão satisfatória devido à pressa em prepar os alimentos. Essa "desvalorização" advém, especialmente, do ciclo de repetições que gera. Já nos finais de semana, a prática do comer em casa ou fora é percebida como um "prazer", geralmente realizada junto aos familiares e/ou amigos, com intervalos de tempo mais flexíveis e de forma mais descontraída, sendo 
que a eventualidade dessa prática lhe confere excepcionalidade, algo a ser valorizado por sua "raridade".

Respondedor: No, muchos fines de semana, la mayoría, subo a mi pueblo y me paso el fin de semana con los amigos, con la familia. (Homem, idade entre 16 e 29 anos, renda $€<500,00 /$ mês, Valência/Espanha, 2014).

Entrevistado: Se eu tiver que comer num restaurante durante a semana é por obrigação, porque eu vou pra trabalhar, final de semana é por prazer, sem preocupação. (Entrevista com oito homens, idades entre 26 e 40 anos, renda não informada, Belo Horizonte/Brasil, 2015, grifos nossos).

Respondent: Yeah Sunday I would say was the most day, either we'll have a roast at mine or mum's or we'll go out, generally on a Sunday. That is a day that we will eat out. (Mulher, idade 31 anos, renda $£$ 65.000,00 a 77.999,00/ ano, Bristol/Reino Unido, 2016).

Em termos de diferença entre os três países, no que corresponde a essas antinomias, verificamos que, nos finais de semana, os entrevistados espanhóis têm uma tendência maior em ir à casa dos pais e, também, aos chamados pueblos (pequenos municípios que se parecem mais como comunidades ${ }^{11}$ ), onde aproveitam para saborear uma "boa comida" - como costumam fazer referência -, além de socializar e rever amigos e familiares. Para os entrevistados brasileiros, a prática de juntar a família e socializar em torno da comida nos finais de semana também ocorre, sendo muito característica a saída aos domingos para ir a churrascarias. Para os britânicos, há também socialização em torno da comida, com familiares e amigos aos finais de semana. Os entrevistados britânicos costumam se deslocar até a casa de parentes ou viajar até cidades próximas para desfrutar de um bom restaurante. Porém, verificou-se também que surge, com maior frequência, a modalidade do comer fora na forma de takeaway aos finais de semana.

Em diálogo com a teoria, tais características demonstram que a formação de conjuntos arranjados de práticas depende intrinsecamente dos contextos

11 Segundo dados do INE (2015), dos mais de 8.000 municípios que formam a Espanha, 1.222 possuem menos de 100 habitantes, ou seja, $15,28 \%$. 
efêmeros em que se constituem e dos quais depende a própria resiliência desses conjuntos. Com efeito, é possível perceber essa característica quando a rotina "clama" por uma pequena variação eventual que, sem a pôr em causa, contribui para que se mantenha.

No que corresponde às estruturas teleoafetivas - as motivações e os fins - que compõem essas práticas em torno do comer, nota-se que a busca pelo prazer ocorre, majoritariamente, aos finais de semana, aproveitando o espaço para uma sociabilidade maior entre familiares e amigos. Já nos dias de semana essa prática é motivada pela necessidade, em que a sociabilidade gira, basicamente, em torno de colegas de trabalho. Essas características são compartilhadas entre os três países, mesmo que com critérios de escolha diversos, variando os espaços e as modalidades. No Reino Unido há uma presença maior da modalidade takeaway e dos restaurantes; no Brasil, destaca-se a ida às churrascarias; e, na Espanha, aos pueblos. A dimensão dos eventos, especialmente quanto à sociabilidade - pela ótica de Warde (2016) -, ganha, portanto, maior destaque quando se analisa a antinomia prazer/obrigação.

\section{Constâncias/Mudanças}

Para concluir a presente análise das práticas sociais sobre as rotinas alimentares, esta subseção trata das mudanças que ocorrem a partir de determinados condicionantes sociais. As perguntas chaves são: quando as rotinas alimentares mudam e por que mudam, especialmente no que diz respeito ao comer?

As categorias analíticas que surgiram das análises dos dados sugerem que essas mudanças, ou mesmo constâncias, em torno das práticas e rotinas alimentares passam por diferentes condicionantes sociais, sendo alguns de maior e outros de menor impacto. Os fatores de maior impacto foram os que correspondem à presença de filhos, à independência ${ }^{12} \mathrm{e}$ a questões relacionadas com a saúde. Os de menor impacto revelaram-se

${ }^{12} \mathrm{O}$ termo independência refere-se ao momento de saída dos jovens do núcleo familiar. 
tendencialmente mais superficiais e contingentes, destacando-se mudanças: no paladar, na oferta de alimentos, na renda, nas dinâmicas laborais.

Quanto à presença de filhos, por exemplo, essa preocupação verificou-se entre os respondentes dos três países, desde a gestação.

Interviewer: So what sort of baguette do you like and where do you tend to find it? Respondent: Now l've become more specific since pregnancy because there were certain things I couldn't... I tried to avoid... (Mulher, idade 35 anos, renda $£$ 50.000,00 a 64.999,00/ano, Londres/Reino Unido, 2016, grifos nossos).

Entrevistado: Eu me habituei, eu tinha maus hábitos alimentares e por estar grávida tinha que comer bem, comer frutas, verduras e legumes que eu não comia aí passei a gostar, decorrência da minha gravidez. (Entrevista com oito mulheres, idades entre 25 e 40 anos, renda classe C, Rio de Janeiro/Brasil, 2015, grifos nossos).

Respondedor: cuando las crías eran más pequeñas y mientras estuve embarazada y tal sí que leí así algunas cosas de alimentación, de cuantas veces a la semana tenías que comer legumbres, cereales, ta [...] (Entrevista com casal, mulher, idade entre 30 e 44 anos, homem > 64 anos, renda €1.500,00 a 1.999,00/ mês, Nava/Espanha, 2014).

No que corresponde às mudanças nas rotinas alimentares a partir das práticas domésticas, na presença de filhos, foram encontradas as seguintes situações. Para os espanhóis, as mudanças ocorrem por meio da coalescência das práticas sociais em torno do comer. Ou seja, surge uma nova prática que formará novos conjuntos arranjados de práticas, porém sem alterar a estrutura teleoafetiva e o entendimento compartilhado que havia anteriormente. Isso quer dizer que a estrutura teleoafetiva girava antes, e se manteve depois, em torno do valor normativo do cuidar e, desse entendimento compartilhado, decorria a preparação de pratos com verduras, legumes e frutas (alimentos saudáveis para os pais e para as crianças, numa aproximação clara da chamada dieta mediterrânea). No caso brasileiro, ocorreram mudanças mais visíveis em torno das práticas. O valor normativo do cuidar dos outros (filhos) conduz a uma nova prática guiada pelo valor normativo do cuidar de si (os próprios pais e, especialmente, as mães que 
realizam essa mudança já na gestação). Por último, no caso do Reino Unido, as mudanças ocorreram na busca da praticidade que, majoritariamente, se alcançou por meio do takeaway. Mais do que o cuidar, o que parece estar em causa entre os respondentes britânicos é, sobretudo, o alívio das tarefas domésticas, descartando, ao menos esporadicamente, a obrigação da prática do cozinhar.

No que diz respeito ao comer fora de casa, na presença de filhos, importou, ainda, analisar a oferta de fast-food, comida habitualmente considerada de baixa qualidade nutricional. Os casos brasileiros apresentaram uma frequência elevada de pais que têm o hábito de levar os filhos para comer em restaurantes fast-food, como McDonald's, Burguer King etc. Nesse sentido, é possível perceber uma contradição entre os argumentos em torno de uma alimentação saudável, que aparecem com frequência nas falas dos brasileiros, e as práticas em torno do comer fora de casa, sendo que o cuidado com os filhos passa também por agradá-los com uma comida de baixa qualidade nutricional, com a ida em restaurantes do tipo fast-food. Os entrevistados espanhóis também levam seus filhos, eventualmente, para comer nesse tipo de restaurantes, porém com a noção de que é uma comida pouco saudável, chamada por eles de comida basura. ${ }^{13} \mathrm{No}$ que corresponde a essa situação, os casos investigados no Reino Unido mostram que o comer em espaços do tipo fast-food é comum, mas também visto com desconfiança quanto à qualidade nutricional e seus impactos na saúde, sendo contestado, algumas vezes, até mesmo pelas crianças. Notadamente, a dimensão que se destaca aqui são os eventos, em que espaço e tempo reconfiguram a própria prática do comer. Ademais, a dimensão da incorporação também conta, ao destacar tal tipo de comida como basura, no caso espanhol.

Um segundo condicionante que se destaca, como um momento em que tende a haver rupturas na rotina alimentar, é quando ocorre a independência do indivíduo perante sua família. Esse período pode passar por momentos mais solitários, com rotinas alimentares mais individualizadas,

${ }^{13}$ Lixo, na tradução literal. 
ou compartilhados, quando da presença de um(a) companheiro(a). De acordo com os respondentes, este momento ocorre, geralmente, quando o jovem é obrigado a cuidar de si e leva adiante suas escolhas a partir do seu próprio gosto. Trata-se de um período de experimentação, em que novos paladares são testados, ampliando a gramática culinária, antes restrita à decisão alheia e ao ambiente doméstico, com influências diretas na dimensão da incorporação. Mais uma vez, a partir dos dados, é possível constatar essa mudança nos três países.

Respondent: When I was a teenager, when I kind of was out and about at college and then off to university, well I had got more autonomy in my diet, that's when I started eating quite a bit more. (Mulher, idade 30 anos, renda $f$ 30.000,00 a 39.999,00/ano, Bristol/Reino Unido, 2016, grifos nossos).

Entrevistador: ¿cómo ha evolucionado vuestra comida a lo largo del tiempo? Respondedor: Bueno para mi el mayor cambio es en el momento en el que me independizo. (Casal, idades entre 16 e 29 anos, renda $€ 2.500,00$ a 2.999,00/ mês, Madri/Espanha, 2014, grifos nossos).

Entrevistado: antes eu morava com minha mãe e então tinha as refeições direitinho... tinha quem fazia e quem se preocupava com a alimentação e depois fui morar sozinha, aí só comidas amarelas como eu falava - Miojo, pizza, macarrão, aí que acarretou esses problemas de saúde. (Entrevista com três mulheres e cinco homens, idades entre 24 e 40 anos, renda não informada, Belo Horizonte/Brasil, 2011, grifos nossos).

Para os britânicos, notou-se um maior cosmopolitismo em termos de mudança das gramáticas que compõem o comer. Isso se explica, principalmente, em razão da variedade e quantidade de comidas exóticas disponíveis, especialmente em Londres. Já entre os brasileiros observaramse recorrentes situações de "desordem" alimentar, estabelecidas nessa fase de independência que impôs novas rotinas alimentares. Se, antes, os alimentos eram controlados pelos pais, agora são, muito frequentemente, escolhidos e ingeridos de maneira descontrolada. Para isso, contribui o fato de as habilidades culinárias serem, em geral, muito restritas e o uso do 
tempo ser, fora de casa e do controle parental, menos regrado. Alimentos ultraprocessados surgem, assim, como a escolha mais óbvia e, por esse fato, consumidos em maior quantidade e sem horários muito definidos. Quanto aos respondentes espanhóis, foi possível constatar que a saída da casa dos pais gerou rupturas inegáveis nas rotinas alimentares, apesar de menos intensas do que no caso brasileiro. Entre os espanhóis, verificou-se também que muitos jovens, mesmo após alcançarem sua autonomia em torno do comer, mantinham o costume de regressar aos chamados pueblos, fosse para visitar seus familiares e amigos, fosse para experimentar ambientes e comidas mais típicas e/ou tradicionais. Esse é um momento de colocar a "alimentação em dia", pois é quando se resgatam sabores da infância (se um primogénito for o cozinheiro), ou se saboreia uma comida preparada com respeito pelos "saberes/sabores ancestrais". Nesses casos, as dimensões dos menus e dos eventos parecem essenciais para compreender as dinâmicas que se constituem em torno das práticas alimentares.

Quanto ao condicionante que corresponde à saúde, as entrevistas mostram que, nos três países, as mudanças nas rotinas alimentares aparecem com frequência em razão de algum problema de saúde já ocorrido, demonstrando uma influência direta da dimensão da incorporação. Pode ser um acidente vascular, um ataque cardíaco, problemas com diabetes, pressão alta, alergias etc. Muitas vezes, esses incidentes exigem restrições alimentares que implicam seguir recomendações médicas, como diminuir as quantidades de açúcar, sal, carne vermelha, gorduras saturadas.

Respondent: [...] some doctor said, you know, you need to take B12 and you need to rebalance your diet. (Mulher, 31 anos, renda $£ 10.000,00$ a 19.999,00/ ano, Bristol/Reino Unido, 2016, grifos nossos).

Entrevistado: Eu tenho exemplo do meu pai, ele comia errado ... a partir do momento que ele viu o resultado do exame ele começou duas dietas ... então a partir desse momento ele mudou. (Entrevista com cinco mulheres e quatro homens, idades entre 17 e 24 anos, renda classe A/B, Curitiba/Brasil, 2015, grifos nossos). 
Respondedor: [...] tuve una advertencia; un pequeño infarto. Pero infarto es. Entonces, a partir de ahí, disciplinadamente me he puesto a las órdenes de los médicos [...] (Casal, mulher entre 45 e 64 anos, homem > 64 anos, renda $€$ 3.000,00 a 4.999,00/mês, Madri/Espanha, 2014, grifos nossos).

No entanto, entre os entrevistados brasileiros e britânicos, as rupturas nas rotinas alimentares em razão de problemas de saúde tendem a ser maiores, já que sinalizam desordens alimentares com maior frequência. Já para os entrevistados espanhóis tais rupturas apresentam um menor impacto nas rotinas alimentares, em razão de recomendações médicas, ou mesmo em razão de problemas de saúde, já que acreditam ter uma disciplina alimentar que gira em torno de uma dieta menos industrializada e mais saudável.

Entrevistado: ... comecei fastfood no almoço, no jantar ... eu tive um problema no estômago, então eu tive que mudar minha alimentação radicalmente, (Entrevista com seis mulheres e três homens, idades entre 17 e 24 anos, renda não informada, Brasília/Brasil, 2015, grifos nossos).

Interviewer: Have your tastes in food changed over time? Respondent: Yes, since I had the stroke in September, (Mulher, idade 64 anos, renda $£ 30.000,00$ a 40.000,00/ano, Londres/Reino Unido, 2016, grifos nossos).

Entrevistador: ¿tienes en cuenta la salud a la hora de programar la alimentación? Respondedor: Un poco puede que sí. Pero tampoco es una prioridad. (Homem, idade entre 16 e 29 anos, renda $€<500,00 /$ mês, Valência/Espanha, 2014, grifos nossos).

No que diz respeito às mudanças das rotinas alimentares em relação à saúde a partir das práticas sociais, observaram-se as seguintes tendências: tanto no Reino Unido quanto no Brasil parece que alinhar alimentação saudável com o prazer não é uma tarefa fácil, pois as comidas mais "gostosas", segundo os entrevistados, tendem a ser as mais temperadas e mais gordurosas. Isso remete à ocorrência de algumas mudanças, a partir da emergência de uma terceira prática alimentar, como a da diminuição de determinados ingredientes (sal, açúcar), sem necessariamente alterar 
o cardápio, expondo as influências da dimensão dos menus em relação à dimensão da incorporação. Isso também remete a uma mudança em torno das "regras", podendo manter ou alterar a estrutura teleoafetiva original, ou seja, a busca pelo "prazer" alinhada à busca pelo cuidar. No caso dos espanhóis, essa dimensão possui menos importância, passando mais pela coalescência das práticas em torno do comer, porém a partir de uma alimentação que, em geral, eles mesmos alegam ser saudável e saborosa. As mudanças das práticas em torno do comer são percebidas no Brasil e no Reino Unido de forma mais "bifurcada", testemunhando mudanças drásticas na dieta alimentar, geralmente por orientações médicas, alterando, obrigatoriamente, a estrutura teleoafetiva. Estamos, portanto, perante uma situação totalmente voltada para o cuidar. Notadamente, a dimensão da incorporação prevalece nas análises que versam sobre esse condicionante da saúde, variando os conjuntos arranjados de práticas conforme o contexto em que ocorrem, pelas óticas de Warde (2016) e Schatzki (2013).

Quanto aos condicionantes de menor impacto - mais graduais podemos resumir as quatro causas - paladar, oferta, renda e dinâmicas laborais -, da seguinte forma. No que corresponde às mudanças no paladar, verificou-se que ocorrem, ao longo da vida, por influência direta da dimensão da incorporação. Tais processos de mudanças se caracterizam por serem mais graduais, configurando-se por uma mescla das práticas sociais, em que novos arranjos e novas práticas surgem a partir de novas regras, podendo alterar ou não a estrutura teleoafetiva, porém não de maneira brusca. As principais características em cada país são: a) o cosmopolitismo britânico, com ênfase nas viagens e nas imigrações e uma disposição em experimentar novos sabores e mesclar aos já conhecidos pela cultura culinária do seu país; b) o tradicionalismo espanhol, como uma forte conexão com os pueblos, aliada à disposição em manter a chamada dieta "mediterrânea", bem como a valoriazação dos produtos regionais e locais; c) uma mescla entre tradicionalismo/cosmopolitismo brasileiro, percebida nas "misturas" regionais e internacionais de temperos e ingredientes na elaboração dos pratos, sendo que a preocupação com a saúde ganha destaque ao se sacrificar parte desse paladar em sua defesa. 
Com relação ao segundo condicionante de menor impacto - a oferta de alimentos - as análises demonstram que tais mudanças ocorrem de forma gradual, entre uma geração e outra, ou mesmo com intervalos de tempo maiores, com alguns marcos históricos, como pós-Segunda Guerra Mundial, muito presente entre os relatos dos entrevistados britânicos. Os dados apontam que as mudanças em torno das práticas e dos arranjos relativos à oferta de alimentos são mais híbridas, ou seja, não há alterações bruscas em um curto intervalo de tempo. Nota-se que as regras se alteram - impostos, políticas de distribuição de alimentos, estímulo à produção etc. - porém, as estruturas teleoafetivas tendem a sofrer modifiações de forma mais gradual - costume e tradição em plantar e/ou consumir determinado alimento. Com isso, formam-se novos valores normativos a partir dos antigos - consumir menos determinado tipo de alimento ou substituir parcilmente seu consumo -, especialmente pela dimensão dos eventos em que a sociabilidade, o tempo e o espaço são dimensões importantes na conformação dos contextos sociais em que os alimentos circulam. Trata-se, por conseguinte, de um processo lento, em que as práticas mais antigas vão se adaptando aos novos arranjos, principalmente em razão dos artefatos produzidos pelas tecnologias. O Reino Unido se caracteriza por uma oferta alimentar mais cosmopolita, os espanhóis por uma conexão maior entre a modernidade e a tradição (cidade e pueblos) e um sistema de abastecimento que dá suporte à dieta mediterrânea. Já os brasileiros se destacam por uma conexão regional mais ampla e uma limitação de acesso - em termos de mobilidade - entre as comunidades e os centros urbanos (distâncias e infraestrutura), mas também por uma crescente oferta internacional à mesa.

O terceiro condicionamento seria a variação da renda, que baliza significativamente as práticas em torno do comer. Essas mudanças ocorrem, principalmente, quanto ao acesso aos restaurantes, conformando as rotinas alimentares e adaptando-as gradualmente. Observou-se, também, principalmente nos casos analisados no Brasil e na Espanha, que não há uma mudança brusca nos menus, mas uma diminuição na quantidade e/ 
ou na frequência com que se consome determinados tipos de comidas, consideradas mais caras, sendo a prática do uso da "marmita" um recurso comumente utilizado, como uma forma de economizar. No caso britânico, o termo crise não foi mencionado pelos entrevistados, sendo que a prática de economizar aparece poucas vezes atrelada às refeições realizadas fora de casa por necessidade, como ocorre no horário do almoço, mas geralmente associada ao comer fora de casa por diversão.

Por último, percebeu-se que as dinâmicas laborais, como quarto condicionamento, também influenciam as mudanças das práticas em torno do comer, especialmente o comer fora, em que diferentes modalidades são utilizadas, como o comer em restaurantes, uso da "marmita", o uso do refeitório da empresa etc. Quanto à estrutura teleoafetiva, pode variar entre o poupar (tempo e dinheiro) e o cuidar (de si e dos seus). No caso britânico, as mudanças tendem a coalescer, pois as diferentes práticas tendem a se acomodar sem alterar a estrutura teleoafetiva preexistente que as coordena, centrada no valor do poupar, principalmente tempo. De todo modo, essas mudanças tendem a ser graduais - nos três países - e relativamente pouco profundas, tendo em vista que os menus são mantidos, mesmo que ocorra alguma influência de colegas ou do ambiente de trabalho.

\section{Conclusões}

Foi possível verificar, a partir do método comparativo de análise, que as práticas sociais do comer influenciam a formação das rotinas alimentares, na medida em que alguns componentes que as constituem coordenam essas dinâmicas. Esses componentes, a partir da Teoria das Práticas, são as estruturas teleoafetivas, o entendimento compartilhado e as regras. Não obstante, tais componentes são capazes de provocar mudanças nas práticas sociais e, consequentemente, nas rotinas alimentares, especialmente sob um olhar a partir das dimensões dos espaços, dos menus e dos processos de incorporação, seguindo as proposições de Warde (2016) e Schatzki (2019).

Assim, a partir dessas análises, foi possível evidenciar alguns processos que explicam como essas práticas são levadas adiante pelos indivíduos e 
seus coletivos nos três países, analisando as antinomias do comer em casa/ fora de casa, do comer por prazer/obrigação, bem como discutindo os condicionantes que delimitam ou mesmo imprimem mudanças/constâncias nas práticas em torno do comer.

Mesmo que os resultados não possam ser generalizados, devido à natureza amostral dos dados - com origem em diferentes projetos de pesquisa, levados a cabo em cada um dos países, por diferentes grupos as reflexões aqui propostas evidenciam instâncias empíricas importantes, comparativamente muito elucidativas quanto aos contextos sociais analisados, especialmente a partir de um olhar pragmático da Teoria das Práticas Sociais.

Em suma, a partir das antinomias, foi possível perceber o quanto importam os contextos para a composição do que Schatzki (2013) convencionou chamar de "conjunto arranjado de práticas". Tais dinâmicas dependem, em larga medida, de determinados condicionantes que imprimem causalidade às práticas sociais (Schatzki, 2016). Algumas dessas causas podem se apresentar de forma mais impactante na vida dos indivíduos e seus coletivos, como é o caso da presença de filhos, da independência ou mesmo de questões de saúde, embora as consequências variem, dependendo do contexto em que ocorrem, como observado ao se comparar os dados do Brasil, da Espanha e do Reino Unido.

Como contribuição teórica, percebeu-se que tais indicativos demonstram que a unidade de análise apontada por Schatzki (2013) - conjunto arranjado de práticas - como elemento central para a compreensão das mudanças sociais é de extrema relevância. Porém, as conexões que se estabelecem entre as diferentes práticas e arranjos materiais para formar tais conjuntos variam de acordo com os contextos em que ocorrem. Por sua vez, os condicionantes que se destacam como fatores causais desses processos podem ser mais ou menos impactantes para as dinâmicas em que implicam, e, assim, para a própria configuração que aqueles conjuntos irão assumir.

No que corresponde às contribuições empíricas, tornaram-se evidentes diversas tendências e características peculiares de cada país quanto às práticas sociais em torno do comer, especialmente sob as dimensões dos eventos, 
dos menus e dos processos de incorporação propostas por Warde (2016). Foi possível notar um cosmopolitismo maior em torno da alimentação no Reino Unido, com características que parecem ter sido adquiridas pelo acolhimento de largas comunidades imigrantes, pelas viagens a outros países, pela oferta alimentar de produtos importados e pelos cardápios internacionais de restaurantes. No Brasil, essa parece ser uma tendência emergente, porém há uma mescla entre essa tendência de internacionalização dos menus e o tradicionalismo e regionalismo culinários, misturando produtos nacionais com receitas internacionais, ou mesmo adaptando as receitas regionais às tendências mundiais, com especial destaque às preocupações em torno da saúde. No que diz respeito aos espanhóis, em comparação ao Reino Unido e ao Brasil, é o país mais tradicional em termos culinários, com uma forte conexão com os chamados pueblos, sendo que as comidas exóticas, além de não serem uma opção usual, quando apreciadas, parecem ser realizadas de forma a "variar" o cardápio, influenciando muito pouco a culinária nacional. Pontua-se que essas conclusões empíricas não podem ser generalizadas para o conjunto dos países, sendo necessários estudos situacionais mais específicos, a fim de demonstrar como tais características mais genéricas se manifestam em diferentes contextos

Maycon Noremberg Schubert é professor adjunto no Departamento de Sociologia da Universidade Federal do Rio Grande do Sul e membro permanente dos Programas de PósGraduação em Desenvolvimento Rural e Pós-Graduação em Sociologia da Universidade Federal do Rio Grande do Sul.

$\triangle$ maycon.schubert@gmail.com

Sergio Schneider é professor titular do Departamento de Sociologia e membro permanente dos Programas de Pós-Graduação em Desenvolvimento Rural e Pós-Graduação em Sociologia da Universidade Federal do Rio Grande do Sul.

$\bowtie$ schneide@ufrgs.br

Cecilia Díaz Méndez é professora catedrática do Departamento de Sociologia da Universidad de Oviedo e coordenadora do Grupo de Investigación en Sociología de la Alimentación.

$\bowtie$ cecilia@uniovi.es 


\section{Referências}

1. BARBOSA, Livia. A ética e a estética na alimentação contemporânea. In: CRUZ, Fabiana T.; MATTE, Alesandra; SCHNEIDER, Sergio. (Orgs.). Produção, consumo e abastecimento de alimentos: desafios e novas estratégias. Porto Alegre: UFRGS, 2016. p. 95-124.

2. BARBOSA, Livia. Feijão com arroz: O Brasil no prato dos brasileiros. Horizontes Antropológicos, v. 13, n. 28, p. 87-116, jul/dez, 2007. https://doi.org/10.1590/ S0104-71832007000200005

3. BARDIN, Laurence. Análise de conteúdo. Lisboa: Edições 70, 2011.

4. DÍAZ-MÉNDEZ, Cecilia; GARCIA-ESPEJO, Isabel. La mirada sociológica hacia la alimentación: análisis crítico del desarrollo de la investigación en el campo alimentario. Política y Sociedad, v. 51, n. 1, p. 15-49, 2014.

5. DÍAZ-MÉNDEZ, Cecilia; GARCIA-ESPEJO, Isabel. Eating out in Spain: motivations, sociability and consumer contexts. Appetite, v. 119, p. 14-22, 2017. https://doi.org/10.1016/j.appet.2017.03.047

6. GARCIA, Keilla R.; GOMES, Joneval Z. A marmita como utensílio para a qualidade de vida: o perfil do consumidor brasileiro. In: CONGRESSO DE PESQUISA E EXTENSÃO DA FSG, IV, 2016, Caxias do Sul. Anais [...]. Caxias do Sul: Faculdade da Serra Gaúcha, 2016. p. 822-839.

7. HERRERA-RACIONERO, Paloma; LIZCANO, Emmánuel F. Los significados de comer fuera. RES: Revista Española de Sociología, v. 27, n. 2, p. 237-249, 2018. https://doi.org/10.22325/fes/res.2018.40

8. JULIER, Alice P. Meals: "Eating in" and "Eating out". In: MURCOTT, Anne; BELASCO, Warren; JACKSON, Peter. The handbook of food research. Londres: Bloomsbury Publishing Plc., 2013. p. 338-351.

9. KELLE, Udo. Análise com auxílio de computador: codificação e indexação. In: BAUER, Martin W.; GASKELL, George (Eds.). Pesquisa qualitativa com texto, imagem e som: um manual prático. 10. ed. São Paulo: Editora Vozes, 2012. p. 393-415.

10. KRAIG, Bruce; SEN, Colleen. Street food around the world: a encyclopedia of food and culture. Santa Barbara: ABC-CLIO, 2013.

11. NEUMAN, Nicklas. On the engagement with social theory in food studies: cultural symbols and social practices. Food, Culture \& Society, v. 22, n. 1, p. 78-94, 2019. https://doi.org/10.1080/15528014.2018.1547069

12. PETERS, Gabriel. A virada praxiológica. Revista Crítica de Ciências Sociais, n. 123, p. 167-188, dez. 2020. https://doi.org/10.4000/rccs.11308

13. RECKWITZ, Andreas. The status of "material" in theories of culture: from "social structures" to "artefacts". Journal for the Theory of Social Behaviour, v. 32, n. 2, p. 195-217, 2002a. http://doi.org/10.1111/1468-5914.00183 
14. RECKWITZ, Andreas. Toward a theory of social practices: a development in culturalist theorizing. European Journal of Social Theory, v. 5, n. 2, pp. 243-263, 2002b. https://doi.org/10.1177/13684310222225432

15. SCHATZKI, Theodore. Social change in a material world. Nova York: Routledge, 2019.

16. SCHATZKI, Theodore. Multiplicity in social theory and practice ontology. In: JONAS, Michael; LITTIG, Beate. A praxeological political analysis. Nova York: Routledge, 2017. p. 17-34.

17. SCHATZKI, Theodore. Keeping tracking of large phenomena. Geographische Zeitschrift, v. 104, n. 1, p. 4-24, 2016.

18. SCHATZKI, Theodore. The edge of change: on the emergence, persistence, and dissolution of practices. In: SHOVE, Elizabeth; SPURLING, Nicola (Eds.). Sustainable practices: social theory and climate change. Nova York: Routledge, 2013. p. 31-46.

19. SCHATZKI, Theodore. The site of social: a philosophical account of the constitution of social and change. Penn State University Park: Pennsylvania State University Press, 2002.

20. SCHATZKI, Theodore. Practice mind-ed orders. In: SCHATZKI, Theodore; CETINA, Karin K.; SAVIGNY, Eike V. The practice turn in contemporary theory. Nova York: Routledge, 2001. p. 42-55.

21. SCHATZKI, Theodore. Social practices: a Wittgensteinian approach to human activity and the social. Cambridge: Cambridge University Press, 1996.

22. SHOVE, Elizabeth; PANTZAR, Mika; WATSON, Matt. The dynammics of social practice: everyday life and how it changes. Londres: Editora SAGE, 2012.

23. SHOVE, Elizabeth; SPURLING, Nicola (Eds.). Sustainable practices: social theory and climate change. Nova York: Routledge, 2013.

24. SIMMEL, Georg. Sociologia da refeição. Estudos históricos, v. 1, n 33, p. 159166, 2004 [1910].

25. SOUTHERTON, Dale. Habits, routines and temporalities of consumption: from individual behaviours to the reproduction of everyday practices. Time \& Society, v. 22, n. 3, p. 335-355, 2012. https://doi.org/10.1177\%2F0961463X12464228

26. WARDE, Alan. Consumption: a sociological analysis. Londres: Palgrave Macmillan, 2017.

27. WARDE, Alan. The practice of eating. Cambridge: Polity, 2016.

28. WARDE, Alan. The sociology of consumption: its recent development. Annual Review of Sociology, v. 41, p. 117-164, 2015. https://doi.org/10.1146/annurevsoc-071913-043208 
29. WARDE, Alan. What sort of a practice is eating? In: SHOVE, Elizabeth; SPURLING, Nicola. Sustainable practices: social theory and climate change. Londres: Routledge, 2013. p. 17-30.

30. WARDE, Alan. Consumption, food and taste: culinary antinomies and commodity culture. Londres: SAGE publications, 1997.

31. WARDE, Alan; MARTENS, Lydia. Eating out: social differentiation, consumption and pleasure. Nova York: Cambridge University Press, 2003. 
